\title{
Term pregnancy with large anterior wall intramural fibroid: an intra- operative challenge
}

\author{
Seema Mehrotra*, Urmila Singh, Vandana Solanki, Nidhi Shanker
}

Department of Obstetrics and Gynecology, King George's Medical University, Lucknow, Uttar Pradesh, India

Received: 08 January 2019

Accepted: 11 February 2019

\section{*Correspondence:}

Dr. Seema Mehrotra,

E-mail: mehrotra.seema@gmail.com

Copyright: (C) the author(s), publisher and licensee Medip Academy. This is an open-access article distributed under the terms of the Creative Commons Attribution Non-Commercial License, which permits unrestricted non-commercial use, distribution, and reproduction in any medium, provided the original work is properly cited.

\begin{abstract}
Leiomyomas are the most common benign smooth muscle tumors of the uterus. The incidence during pregnancy ranges between 1.6 to $10 \%$. The management of fibroids encountered during caesarean section poses a therapeutic dilemma. We present a case of giant anterior wall lower segment leiomyoma complicating term pregnancy which posed a great surgical challenge. Myomectomy was performed before delivering the baby by lower segment caesarean section by locating the tumor free area using preoperative ultrasound. The tumor mass weighed $3 \mathrm{~kg}$. This case highlights the preoperative use of ultrasound in emergency caesarean section to avoid classical caesarean section and to prevent fetal mortality and morbidity by avoiding time consuming caesarean myomectomy before the delivery of the baby.
\end{abstract}

Keywords: Fibroid uterus, Myomectomy, Pregnancy

\section{INTRODUCTION}

Leiomyomas are the most common benign smooth muscle tumors of the uterus. The incidence during pregnancy ranges between 1.6 to $10 \%$. The management of fibroids encountered during caesarean section poses a therapeutic dilemma. We present a case of giant anterior wall lower segment leiomyoma complicating term pregnancy which posed a great surgical challenge. Myomectomy was performed before delivering the baby by lower segment caesarean section by locating the tumor free area using preoperative ultrasound. The tumor mass weighed $3 \mathrm{~kg}$. This case highlights the preoperative use of ultrasound in emergency caesarean section to avoid classical caesarean section and to prevent fetal mortality and morbidity by avoiding time consuming caesarean myomectomy before the delivery of the baby. Uterine fibroids are extremely common benign smooth muscle tumors of the uterus. The overall incidence varies from $40-60 \%$ by age 35 years and 70 to $80 \%$ by age $50 .^{1}$

The prevalence of uterine fibroids in pregnancy varies between 1.6 and 10.7 percent depending upon the trimester of assessment and the size threshold. ${ }^{2-5}$ Uterine myomas are observed in pregnancy more frequently now than in past because of the increasing age of child bearing and wide spread use of ultrasound. Myomas are generally asymptomatic in pregnancy but $10-30 \%$ of the women may present with some form of complication like first trimester losses, pressure symptoms, pain of red degeneration, premature labour, premature rupture of membranes, malpresentations, antepartum haemorrhage, obstructed labour, retained placenta and post-partum haemorrhage. ${ }^{6-8}$ Once the diagnosis of myoma is confirmed by USG, management of fibroids encountered during caesarean delivery poses a therapeutic dilemma. 


\section{CASE REPORT}

Mrs. X, 30 years female, primigravida was referred to our antenatal OPD from a private clinic as a case of 22 weeks pregnancy with large pelvic mass. Her medical, personal history, past and family history was not significant. On general examination general condition was fair, pallor absent, PR-70/min, BP-100/68mm of Hg, height $-150 \mathrm{~cm}$, weight-54 kg. Per abdominal examination revealed fundal height 28 weeks which was more than period of gestation and uterus was relaxed. Investigation: $\mathrm{Hb}$ $9.5 \mathrm{mg} \%$, blood group was B +ve. Screening blood sugar was $103 \mathrm{mg} \%$, urine routine microscopy and viral markers were normal.

Ultrasound at the gestational age of 24 weeks showed anatomically normal, live fetus corresponding to the gestational age. Placenta was anterior, mid cavity, liquor adequate and a large intramural fibroid of size $14.66 \mathrm{~cm} \mathrm{x}$ $12 \mathrm{~cm} \times 8.76 \mathrm{~cm}$ on left anterio-lateral wall of uterus. Six weeks later, a repeat ultrasound examination revealed an appropriately grown fetus at 30 weeks with large intramural fibroid of $17.24 \mathrm{~cm} \times 13.25 \mathrm{~cm}$.

On anterior wall of uterus extending into the lower segment. At 35 weeks USG, fetus had breech presentation with corresponding fetal parameter and a large fibroid which has grown to the size of $23 \times 16 \mathrm{~cm}$ involving anterior wall of the uterus extending into lower segment.

The woman was kept on regular antenatal cheek up. She was advised rest, fetal movement count, iron and calcium supplementation. Hemoglobin estimation and obstetrical ultrasound was performed at regular interval to assess the fetal growth and size of the fibroid. Steroid was given at 33 weeks for fetal lung maturity.

The women and her relatives were counseled for various complications of pregnancy with fibroid like preterm labour, preterm premature rupture of membranes, intrauterine growth restriction, antepartum hemorrhage and post-partum hemorrhage.

Two units of blood were arranged. During the course of pregnancy, myoma showed progressive increase in size. The patient was planned for elective caesarean section at 37 weeks.

However, she had loss of fetal movements and a pathological cardiotocograph (CTG) at 36 weeks. She was taken up for emergency caesarean section after arranging 2 units of blood. Also consent for caesarean hysterectomy was sought in case of any eventuality.

Emergency caesarean section was done under spinal anaesthesia. Abdomen was opened by right para median longitudinal incision. Preoperatively there was a large intramural fibroid involving anterior wall and lower uterine segment (Figure 1), and exact location of fetal parts could not be made out.

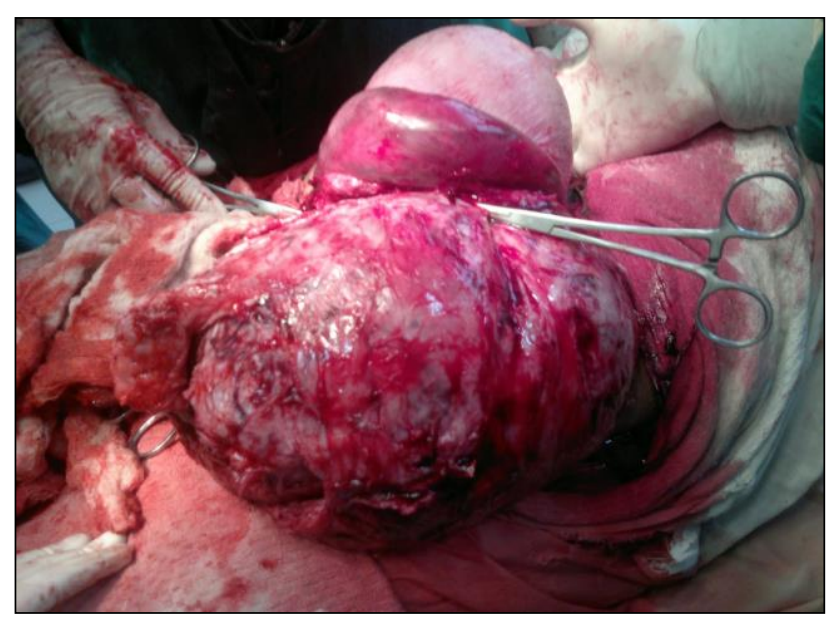

Figure 1: Large lower segment intramural fibroid.

The decision where to place the incision was challenging. The incision into the lower uterine segment was not helpful as the fibroid was obstructing entry into the uterine cavity. Classical caesarean section would have hampered her future obstetrics plans. The third option was to perform caesarean myomectomy followed by delivery of the baby, but this was a time-consuming option and baby had to be delivered quickly as fetus was in distress. Therefore, per operative ultrasound probe using full aseptic precaution was used to find out tumor free area between the fetus and uterine wall. Tumor free area and breech presentation was identified on right side, high above the internal os. L-Shaped incision was given on right side of lower segment and extended left over the fibroid. Uterine cavity was subsequently entered and baby weighting $2.6 \mathrm{~kg}$ at good Apgar score, was delivered by breech extraction. Following delivery of the baby caesarean myomectomy was done and huge fibroid weighing $3 \mathrm{~kg}$ was removed through the same incision. After hemostatic sutures uterus was closed in 3 layers. Two units of blood was transfused, one intra operative and another post-operative. The postoperative period was uneventful. 6 weeks postpartum the uterus was well involuted and was of normal size. Histopathological diagnosis of tumor was benign intramural leiyomyoma.

\section{DISCUSSION}

The management of fibroids encountered during caesarean section poses a therapeutic dilemma. The term uterus receives about $17 \%$ of cardiac output which results in increased vascularity of the uterus during pregnancy. Therefore, myomectomy during caesarean section has traditionally been discouraged due to fear of intractable hemorrhage. Studies have reported that hemorrhage during caesarean myomectomy can be so severe that it can often necessitate hysterectomy. ${ }^{9-14}$ Earlier studies have reported that it is better to avoid myomectomy during caesarean section with the exception of small and 
medium size pendenculated fibroid because of potential complications like intraoperative hemorrhage need for blood transfusion and post-partum fever. ${ }^{15-17}$ However, a number of authors have recently shown that myomectomy at caesarean section does not increase the risk of hemorrhage. ${ }^{18}$

Case control study of 47 patients with caesarean myomectomy and 94 patients who had caesarean section without removal of fibroids did not show any significant difference in complication rate, except that operative time was more in caesarean myomectomy. ${ }^{19}$ The commonest indication for performing myomectomy during caesarean section is the presence of anterior lower segment uterine fibroid on the proposed line of incision. This can avoid a classical uterine incision which otherwise will jeopardize the woman's future obstetric plans. Recently few researchers have advocated removal large anterior wall fibroid first so as to facilitate easy delivery of the baby thorough lower segment caesarean section. ${ }^{11,12,20}$ However this was not possible in our case due to fetal distress which warranted quick delivery.

Apart from being a rare case of colossal size, anterior wall fibroid with pregnancy, our case highlights the per operative use of ultrasound in emergency case to prevent fetal mortality and morbidity by avoiding the timeconsuming caesarean myomectomy before the delivery of baby.

Caesarean myomectomy which was once considered a taboo should now be reconsidered. Enucleation of the fibroid is technically easier in pregnant uterus due to greater looseness of the capsule. ${ }^{9}$ Apart from being a cost-effective procedure in a low resource constrain setting, caesarean myomectomy obviates the need for interval myomectomy and decreased complications associated with fibroids in subsequent pregnancies. ${ }^{21,22}$

Also scar integrity for caesarean myomectomy has been shown to be better than that following interval myomectomy, when assessed with serial ultrasound scan in subsequent pregnancies and subsequent caesarean section. In selected patients and in experienced hands myomectomy (before or after delivery of the baby) can be a safe procedure. ${ }^{23}$

\section{Clinical significance}

- Fibroid uterus in an important differential diagnosis of pregnancy with pelvis mass

- Caesarean myomectomy, before and after delivering the baby can be considered in selected patients by experienced obstetrician

- Tumor free area should be located by preoperative ultrasound before performing caesarean section in woman with huge anterior wall lower segment fibroid so as to plan the site of incision in lower segment.
Funding: No funding sources

Conflict of interest: None declared

Ethical approval: Not required

\section{REFERENCES}

1. Baird DD, Dunson DB, Hill MC, Cousins D, Schectman JM. High cumulative incidence of uterine leiomyoma in black and white women: ultrasound evidence. Am J Obstet Gynecol. 2003;188(1):100-7.

2. Qidwai GI, Caughey AB, Jacoby AF. Obstetric outcomes in women with sonographically identified uterine leiomyomata. Obstet Gynecol. 2006;107(2):376-82.

3. Ouyang DW, Economy KE, Norwitz ER. Obstetric complications of fibroids. Obstet Gynecol Clinic. 2006;33(1):153-69.

4. Stout MJ, Odibo AO, Graseck AS, Macones GA, Crane JP, Cahill AG. Leiomyomas at routine secondtrimester ultrasound examination and adverse obstetric outcomes. Obstet Gynecol. 2010;116(5):1056-63.

5. Vergani P, Locatelli A, Ghidini A, Andreani M, Sala F, Pezzullo JC. Large Uterine leiomyomata and risk of caesarean delivery. Obstet Gynaecol. 2007;109:410-4.

6. Panchal DN, Doshi HU, Singh P, Rohit P,eds, Coexisting large fibroid and pregnancy.23rd ed. William Obstetrics Mac Grow Hill. 2010; 40: 903 904.

7. James PR, Helen HR, Barry SM. The clinical significance of leiomyoma in pregnancy. Am J Obstet Gynecol. 1989;160:1212-16.

8. Lolis DE, Kalantaridou SN, Makrydimas G, Sotiriadis A, Navrozoglou I, Zikopoulos K, et al. Successful myomectomy during pregnancy. Human Reprod. 2003;18(8):1699-702.

9. Kwawukume EY. Caesarean myomectomy. African J Reproduct Health. 2002:38-43.

10. Ehigieba AE, AndaAB, Ojobo SI . Moymomectomy during caesarean section. Int $\mathrm{J}$ Gynecol Obstet. 2001;75: 21-5.

11. Omar SZ, Sivanesaratnam V, Damodaran P. Large lower segment myoma: Myomectomy at lower segment section- a report of two cases. Singapore Med J. 1999;40:109.

12. Sudhir A, Sebanti G. Cesarean myomectomy-A study of 14 cases. J Obstet Gynecol India. 2006;56(6):486-8.

13. Exacoustòs CA, Rosati P. Ultrasound diagnosis of uterine myomas and complications in pregnancy. Obstet Gynecol. 1993;82(1):97-101.

14. Hasan F, Arumugam K, Sivanesaratnam V. Uterine leiomyomata in pregnancy. Int $\mathbf{J}$ Gynecol Obstet. 1991;34(1):45-8.

15. Ortac F, Gungor M, Sonmezer M. Myomectomy during caesarean section. Int $\mathrm{J}$ Gynecol Obstet. 1999;67:189-98. 
16. Panchal DN, Doshi HU, Singh P, Rohit P. Coexisting large fibroid and pregnancy. Gujarat Med 1 J. 2012;67 (2): 110-2.

17. Wolabi AT, Kuti O, Loto OM, Markendi OM, Adeyemi AB. Caesarean myomectomy- a safe procedure. A retrospective case controlled study. NJ Obstet Gynaecol. 2007; 2 ( 2 ): 59-62.

18. Machado LS, Gowri V, Al-Riyami N, Al-Kharusi L. Caesarean myomectomy: feasibility and safety. Sultan Qaboos Univ Med J. 2012;12(2):190.

19. Hassiakos D, Christopoulos P, Vitoratos N, Xarchoulakou E, Vaggos G, Papadias K. Myomectomy during cesarean section: a safe procedure? Annals New York Acad Sci. 2006;1092(1):408-13.

20. Leanza V, Fichera S, Leanza G, Cannizzara MA. Huge Fibroid removed during caesarean section with uterus preservation. A case reports. Ann. Ital.Chir.2011; 82:75-7.
21. Omigbodun AO, Fawole AO. Myomectomy during pregnancy and delivery: is it safe?: Commentary. Trop J Obstet Gynaecol.2005;22(1):1-3.

22. Awoleke JO. Myomectomy during caesarean birth in fibroid-endemic, low-resource settings. Obstet Gynecol Internat. 2013;2013.

23. Cobellis L, Messali EM, Stradella L, Pecori E, Gioino E, De EL, et al. Myomectomy during cesarean section and outside pregnancy. Different outcomes of scars. Minerva Ginecol. 2002;54(6):483-6.

Cite this article as: Mehrotra S, Singh U, Solanki V, Shanker N. Term pregnancy with large anterior wall intramural fibroid: an intra-operative challenge. Int $\mathbf{J}$ Reprod Contracept Obstet Gynecol 2019;8:1696-9. 